\title{
Large-scale disasters and the insurance industry ${ }^{1}$
}

\author{
by \\ Walter Krämer \\ Fachbereich Statistik, Universität Dortmund, Germany \\ and \\ Sebastian Schich \\ OECD, Division for Financial Market Affairs, Paris
}

February2005

\begin{abstract}
We investigate the effect of the 20 largest - in terms of insured losses - man-made or natural disasters on the insurance industry. We show via an event study that insurance markets worldwide are quite resilient to unexpected losses to capital and are even outperforming the general market subsequent to great disasters.
\end{abstract}

Keywords: disaster, insurance industry, event-study.

\footnotetext{
${ }^{1}$ Research supported by Deutsche Forschungsgemeinschaft under SFB 475.
} 


\section{Introduction}

Large scale disasters, whether man-made such as the terrorist attack on the World Trade Center in 2001, or natural such as the recent tsunami catastrophe in the Indian Ocean, need not necessarily imply a disaster for the insurance industry. There is a well documented tendency (see e.g. Shelor et al. 1992 or Cummins and Danzon 1997) for premiums to rise after such events which might or might not outweigh unexpected losses to capital.

The mechanism which establishes a new market equilibrium subsequent to such catastrophes is discussed in detail elsewhere (see e.g. Gron 1994, Froot and O'Connel 1999, or Cummins and Lewis 2002) and shall not concern us here. Rather, we answer the empirical question whether disaster-related factors which raise premiums, such as an outward shift of the demand curve or a decrease in the supply of insurance induced by an increase in the cost of capital (Cummins and Danzon 1997), are able to overcompensate the adverse shock to equity, at least in the eyes of investors. To this extent, we examine the 20 all-time most costly disasters (in terms of insured property losses) and determine via an event-study whether the insurance-industry experienced any positive or negative abnormal returns thereafter. Positive abnormal returns subsequent to a shock are interpreted as evidence that investors believe that premium increases will be sufficient to make up for capital losses resulting from the disaster, while negative abnormal returns are interpreted as indicating the opposite.

There is ample evidence that the disasters in our study can indeed be viewed as unexpected shocks not fully anticipated in premium pricing. This is most obviously true for the September 11 terrorist attacks. Prior to these attacks, terrorism cover was generally not a separate line of insurance. Typically, it was not even mentioned in insurance policies and (all-risk physical damage) policies would automatically cover losses associated with such events, as the risk was perceived to be insignificantly low. Previous terrorist attacks in the United States like the first WTC bombing in 1993 or the Oklahoma City bombing in 1995 were discounted as non-recurring events in a world were attacks on U.S. life and property occurred exclusively outside the United 
States. In the case of natural catastrophes such as Hurricane Andrew or the Northridge earthquake, insurers were aware of the potential hazard, but seemed to underestimate both the probability and the severity of the events. This is what transpires from a perusal of the specialized insurance literature and it is also reflected in the large discrepancy between insured losses and premium incomes collected prior to the events. For example, it has been reported that insurance companies' pay-outs related to Hurricane Andrew in Florida exceeded by 50 per cent all premiums collected in that state for the past 22 years, while insured losses related to the Northridge earthquake alone were equal to the entire amount of premiums collected in the $20^{\text {th }}$ century for earthquake insurance (Arnold 2002). Many industry observers have argued that in general the premiums collected during the 1990s were too low to compensate for the large pay-outs related to natural catastrophes during that decade, which included typhoons in Japan and winterstorms in Europe.

Below we investigate whether or not such unexpected losses are compensated by subsequent changes of parameters in the insurance industry. Other than most previous investigations of the effects of disasters on the insurance industry, we broaden our data base to also include disasters and markets outside the US. Contrary to e. g. aiuppa et al (1993), Lamb (1995) or Cummins and Lewis (2002), we also focus on the insurance industry as such, not on individual insurance companies. We also use three different estimates of abnormal returns to make sure that our results are not an artifact of the procedure which is employed to isolate the effect of an event.

\section{The models and the data}

Table 1, based on estimates reported by Swiss Re (2004), lists the disasters included in our study. It is headed by the September 11 terrorist attacks in 2001, closely followed by Hurricane Andrew, which in August 1992 struck South Florida, Louisiana and the Bahamas with winds of up to 140 miles an hour, and the Northridge earthquake in 1994. As the table only lists property and business interruption losses, excluding life and liability insurance losses, the overall insured losses from the September 11 
Table 1: The 20 worst catastrophes in terms of insured losses

\begin{tabular}{|c|c|c|c|}
\hline Insured loss $^{1}$ & Date & Event & Country \\
\hline 21.062 & 11.09 .2001 & $\begin{array}{l}\text { Terrorist attacks on WTC, } \\
\text { Pentagon and other buildings }\end{array}$ & United States \\
\hline 20.900 & 23.08 .1992 & Hurricane Andrew & United States \\
\hline 17.312 & 17.01.1994 & Northridge earthquake & United States \\
\hline 11.000 & 02.09 .2004 & Hurricane Ivan & United States \\
\hline 7.598 & 27.09.1991 & Typhoon Mireille & Japan \\
\hline 7.000 & 11.08 .2004 & Hurricane Charley & United States \\
\hline 6.441 & 25.01 .1990 & Winterstorm Daria & $\begin{array}{l}\text { France, United } \\
\text { Kingdom, } \\
\text { Germany }\end{array}$ \\
\hline 6.382 & 25.12 .1999 & Winterstorm Lothar & $\begin{array}{l}\text { France, } \\
\text { Switzerland, } \\
\text { Germany }\end{array}$ \\
\hline 6.203 & 15.09 .1989 & Hurricane Hugo & United States \\
\hline 5.000 & 26.08 .2004 & Hurricane Frances & United States \\
\hline 4.839 & 16.10 .1987 & Storm and floods in Europe & $\begin{array}{l}\text { France, UK, } \\
\text { Netherlands }\end{array}$ \\
\hline 4.476 & 25.02 .1990 & Winterstorm Vivian & $\begin{array}{l}\text { France, Germany, } \\
\text { Switzerland, UK, } \\
\text { Netherlands }\end{array}$ \\
\hline 4.445 & 22.09.1999 & Typhoon Bart & Japan \\
\hline 4.000 & 13.09 .2004 & Hurricane Jeanne & United States \\
\hline 3.969 & 28.09.1998 & Hurricane George & United States \\
\hline 3.261 & 05.06 .2001 & Tropical storm Allison & United States \\
\hline 3.205 & 02.05 .2003 & Thunderstorms, tornadoes, hail & United States \\
\hline 3.100 & 06.07 .1988 & $\begin{array}{l}\text { Explosion on Piper Alpha } \\
\text { drilling platform }\end{array}$ & United Kingdom \\
\hline
\end{tabular}

1 In USD millions, indexed to 2003. Only insured property losses. Losses for 2004 are preliminary estimates. For hurricanes, event dates dates indicate landfall. Source: Swiss Re (2004a,b) and author additions.

terrorist attacks, and also from some of the other catastrophes, are of course much higher than indicated in the table. As regards the areas affected, the United States are the country most often hit by the catastrophic events shown in Table 1 . They 
experienced eleven events from different categories, including hurricanes, terrorist attacks, earthquakes and storms, with four hurricanes occurring in 2004 alone. Japan experienced three typhoons and one earthquake. Europe was hit by three winterstorms in 1990 and 1999 and by storm and floods in 1987 which affected more than one country at a time, and an explosion on a drilling platform in 1988.

The ranking in table 1 does not correspond to catastrophes in terms of victims. The most costly disaster in this respect in modern times, the 1970 storm and flood catastrophes in Bangladesh and the recent tsunami in the Indian ocean, both with a cost of about 300,000 lives, are not even included in table 1. Similarly, the earthquake in Tangshan in China in 1976, with 250,000 victims, or the tropical Cyclone Gorki in 1991, with 140,00 victims, although gigantic catastrophes in almost any sense, did not induce heavy insurance losses in absolute dollar terms, and are therefore also not included in the table.

For each disaster, and for each country involved, we estimated normal and abnormal returns of the respective insurance industries in three different ways. First, via the conventional market model (MacKinlay 1997)

$$
\mathrm{R}_{\mathrm{it}}=\alpha_{\mathrm{i}}+\beta_{\mathrm{i}} \mathrm{R}_{\mathrm{mt}}+\varepsilon_{\mathrm{it}},
$$

where $R_{i t}$ is the return of an index of the insurance industry in period $t$, and $R_{m t}$ is the return of a broad market index in that period, and where $\alpha_{i}+\beta_{i} R_{m t}$ is the "normal" return to be estimated from the data. Data are daily and range from event day - 200 to event day -1 . Second, via the market-adjusted return model where $\alpha_{i}=0$ and $\beta_{i}=1$. This is mainly to avoid the well known problem of correlation between the regressor and the disturbance term in (1) induced by non-synchronous trading (see e.g. Brown and Warner 1985), which renders conventional least squares estimates of $\beta_{\mathrm{i}}$ inconsistent. As we are using indices rather than individual firms, this potential bias does not seem to be very important here, but it is still useful to have alternative measures of abnormal returns. We therefore also used the constant expected returns model where we set normal returns equal to zero. In addition to providing yet another measure of abnormal performance, this also circumvents the problem that large-scale 
disasters may affect the market (which may be expected almost by the definition of such event), which would imply that both the marked-model based and the markedadjusted abnormal returns do not capture all of the effects of an event.

Following the disaster, we therefore computed daily abnormal returns for the respective local insurance sector via either

$$
\mathrm{AR}_{\mathrm{it}}=\mathrm{R}_{\mathrm{it}}-\hat{\alpha}_{\mathrm{i}}-\hat{\beta}_{\mathrm{i}} \mathrm{R}_{\mathrm{mt}},
$$

where $\hat{\alpha}_{i}$ and $\hat{\beta}_{i}$, respectively, are estimates for $\alpha_{i}$ and $\beta_{i}$ from (1) (the market model), or

$$
\mathrm{AR} *_{\mathrm{it}}=\mathrm{R}_{\mathrm{it}}-\mathrm{R}_{\mathrm{mt}}
$$

(the market adjusted returns model), or

(4) $\quad \mathrm{AR}^{* *} *_{\mathrm{it}}=\mathrm{R}_{\mathrm{it}}$

(the constant expected returns model). The subscript $\mathrm{i}(\mathrm{i}=1, . ., 20)$ indicates the disaster, $\mathrm{R}_{\mathrm{it}}$ is the return of the local insurcance sector (either USA, Japan or Western Europe) on event day $\mathrm{t}$, and $\mathrm{R}_{\mathrm{mt}}$ is the return of the local stock market. Both the total market and insurance industry indices were obtained from Thompson Financial Datastream. The indices for Europe cover mainly the EU (as of 1995) plus Switzerland, which are at the same time the countries affected by the disasters under study here.

In every case, the event window ranges from the event day to event day +29 .

\section{Results}

Table 2 gives the estimates of the respective marked models. It exhibits a considerable variation in regression estimates, even for a given market, which is not compatible with a constant market model across the whole data set. Although the conventional CUSUM-tests fail to reject the null hypothesis that the regression coefficients are 
Table 2: Least Squares estimates of the market model

\begin{tabular}{|c|c|c|c|}
\hline Event & $\begin{array}{c}\text { OLS-estimate } \\
\text { for } \boldsymbol{\alpha}\end{array}$ & $\begin{array}{c}\text { OLS-estimate } \\
\text { for } \boldsymbol{\beta}\end{array}$ & $\mathbf{R}^{\mathbf{2}}$ \\
\hline $09 / 11$ terrorist attacks & -0.00031 & 0,45 & 0,28 \\
\hline Hurricane Andrew & 0,00007 & 0,78 & 0,62 \\
\hline Northridge earthquake & $-0,00032$ & 0,87 & 0,41 \\
\hline Hurricane Ivan & 0,00027 & 0,77 & 0,66 \\
\hline Typhoon Mireille & 0,00023 & 0,94 & 0,66 \\
\hline Hurricane Charley & 0,00030 & 0,75 & 0,64 \\
\hline Winterstorm Daria & 0,00034 & 1,04 & 0,76 \\
\hline Winterstorm Lothar & $-0,00090$ & 1,16 & 0,70 \\
\hline Hurricane Hugo & 0,00065 & 0,85 & 0,68 \\
\hline Hurricane Frances & 0,00034 & 0,78 & 0,68 \\
\hline Storms and Floods & $-0,00087$ & 0,90 & 0,45 \\
\hline Winterstorm Vivian & 0,00049 & 1,06 & 0,79 \\
\hline Typhoon Bart & $-0,00172$ & 0,86 & 0,37 \\
\hline Hurricane Jeanne & 0,00026 & 0,77 & 0,66 \\
\hline Hurricane George & $-0,00005$ & 0,90 & 0,79 \\
\hline Tropical Storm Allison & 0,00071 & 0,49 & 0,26 \\
\hline Tornados & 0,00008 & 0,94 & 0,78 \\
\hline Piper alpha & $-0,00014$ & 0,95 & 0,76 \\
\hline Kobe earthquake & $-0,00010$ & 1,10 & 0,58 \\
\hline Typhoon Songda & $0,00032$. & 1,31 & 0,53 \\
\hline
\end{tabular}

constant throughout the 1987-2004 period which is spanned by the events under study, a standard Chow-test, when for instance applied to the combined $n=400$ data points which were used for the estimation of the market model prior to Hurricane Andrew 
and the 9/11-attacks, clearly rejects the hypothesis of parameter constancy (CUSUMtests fail to do so mainly because in the present context, structural changes are almost orthogonal to the mean regressor, which leads to a very poor power of the tests; see Ploberger and Krämer 1990, 1992). For small subsets of the data of length $n=230$, which were used to estimate the market model and to compute abnormal returns around a particular disaster, the assumption of parameter constancy can however much more easily be maintained.

Figure 1 shows the cumulated excess returns, as computed according to the methods described in section 3. For each event day t, the 20 abnormal returns were averaged (arithmetic mean) prior to cumulating. No matter which measure of abnormal performance is used, the insurance sector suffers on the day of the disaster, but soon recovers according to market-model and market-adjusted returns, even outperforming the market about one week after the disaster, with a small and insignificant negative cumulated return at the end of the post event window.

\section{Figure 1: cumulated abnormal returns}

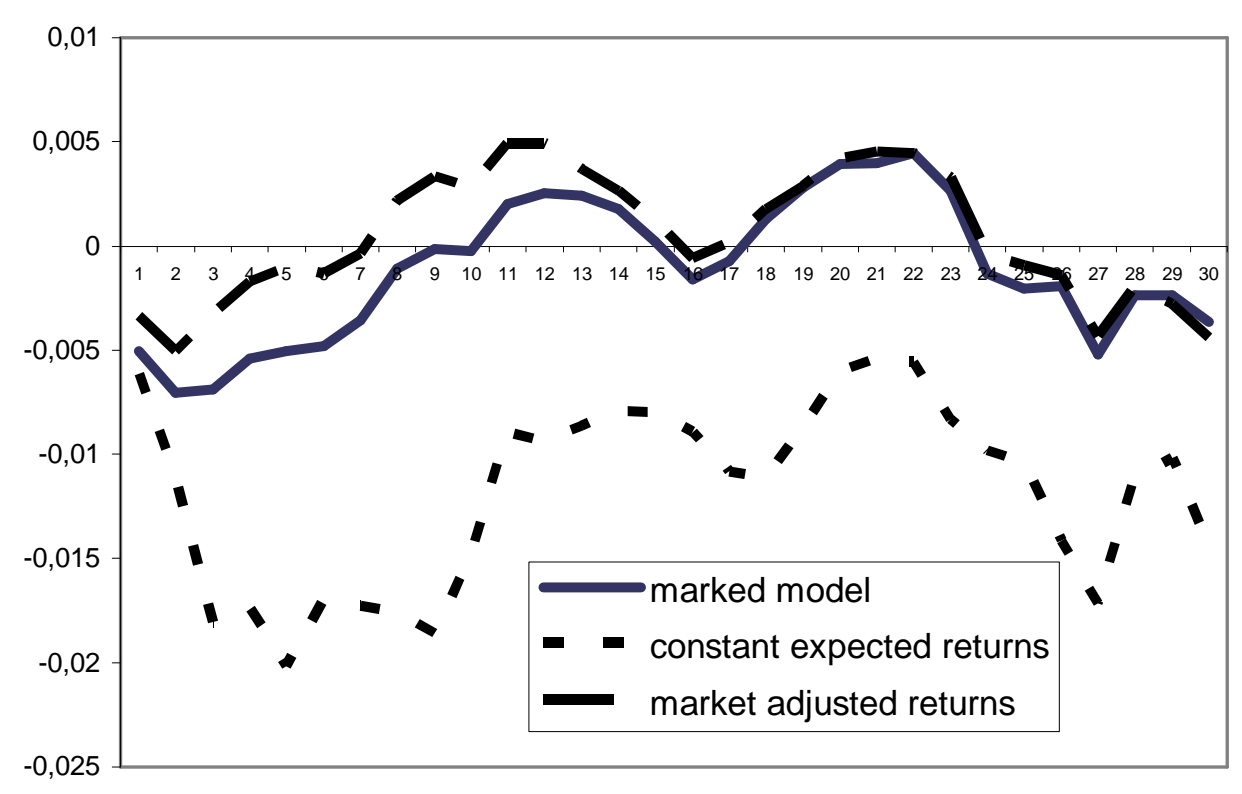

Cumulated unadjusted returns are however negative on average throughout, and significantly so (see below). This is mainly due to the fact that the European and Japanese markets were in general negative subsequent to most disasters. Also, the post 
event window for the 1987 European flood catastrophe includes the October 87 stock market crash, with a decline in the total market index within the post event window of $24 \%$. One these movements of the market are accounted for, remaining returns are only slightly negative or even positive, as seen in figures 2 and 3, which depict abnormal returns for the European and Japanese markets separately.

Figure 2: cumulated abnormal returns Europe

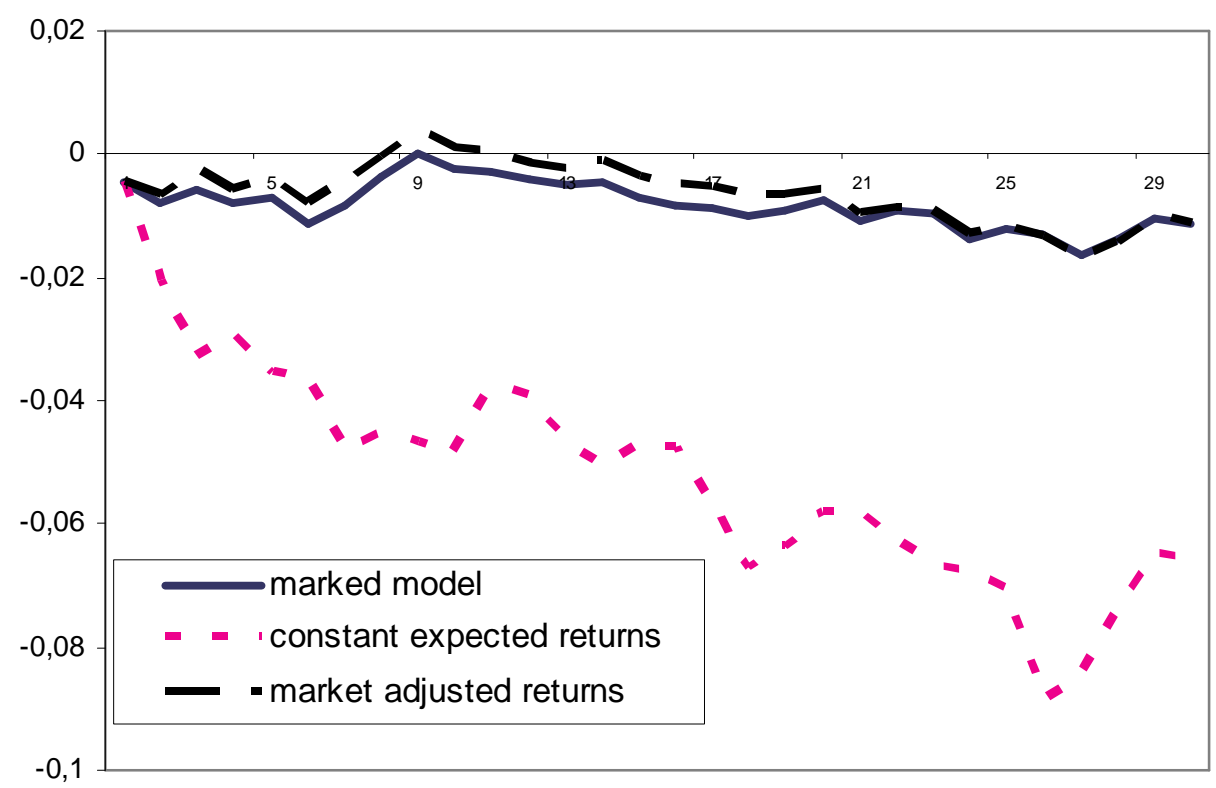

Figure 3: cumulated abnormal returns Japan

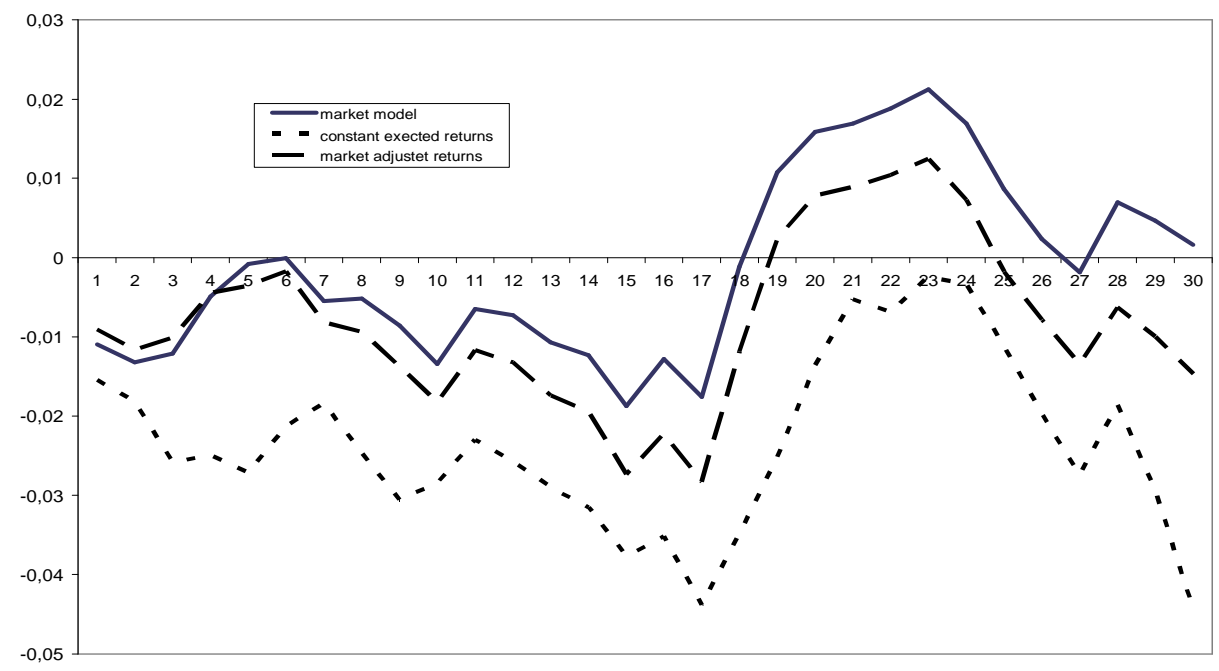


In the US, both the total market and the insurance industry recover fast and show positive returns soon after a disaster. For instance, while both the total market and the insurance industry declined by about $5 \%$ on the day trading resumed after the September 11 attack, they registered a 1\% (market) and 8\% (insurance industry only) increase over the whole post event window. After hurricane Andrew, the insurance sector declined by $1.1 \%$ on day one but increased by $6.8 \%$ over the whole post event window (while the rest of the market remained flat). As is seen in figure 4, both the economy in general and the insurance industry in particular do not seem to suffer much from catastrophes like this.

Figure 4: cumulated abnormal returns USA

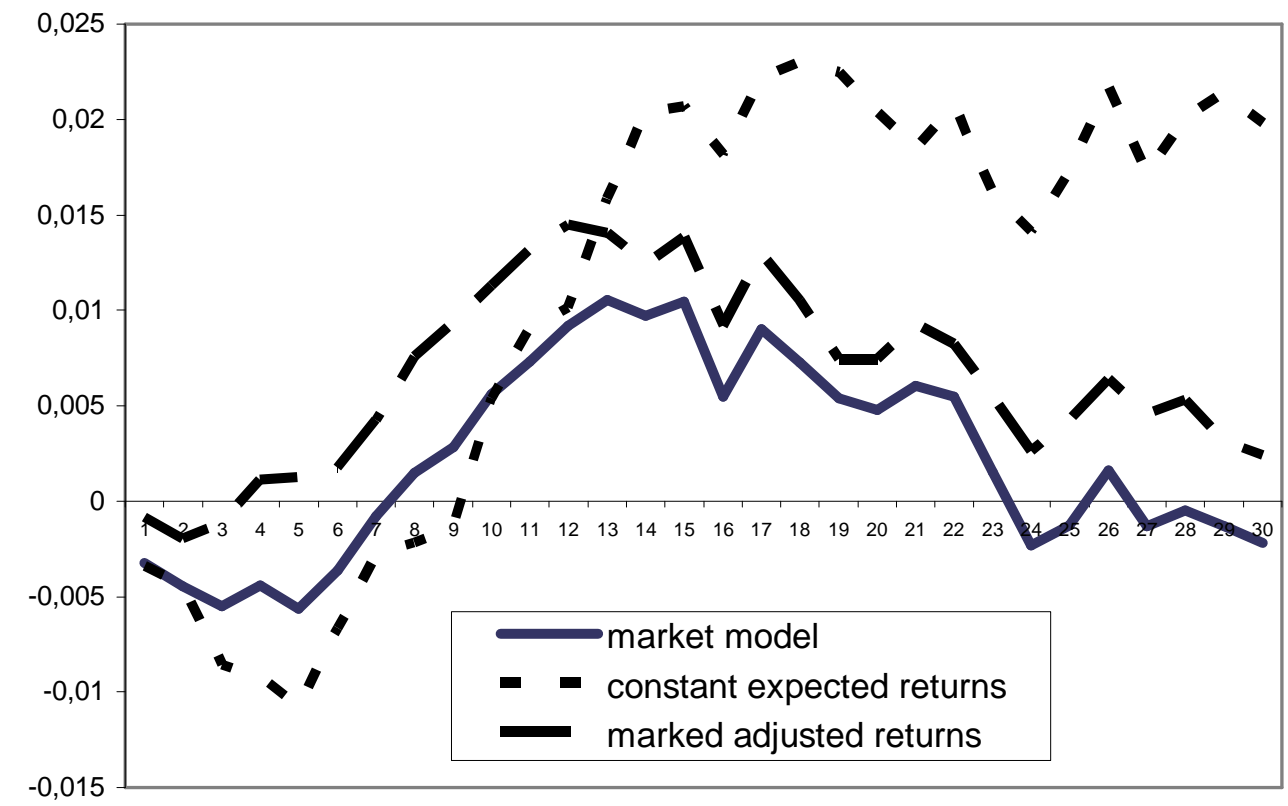

This conclusion is also born out by a formal test of statistical significance. Table 3 shows the abnormal returns as computed according our models, together with estimates of the respective standard deviations. The standard estimate of the standard deviation was obtained by computing, for each event $i$, and for each estimation window, the empirical variances $S_{i}^{2}$ of the abnormal returns form the marked model, the market adjustment model and the constant expected returns model. An estimate $S_{i}$ of the standard deviation of the day 1 abnormal average return is then obtained from 
(5)

$$
\left.\mathrm{S}_{\mathrm{i}}=\left(\left(\mathrm{S}_{1}{ }_{1}+\ldots+\mathrm{S}_{20}^{2}\right) / 400\right)\right)^{1 / 2}
$$

and an estimate of the standard deviation of the cumulated returns is obtained by multiplying this expression by $30^{1 / 2}$.

Table 3: Average abnormal returns and standard deviations

\begin{tabular}{|c|c|c|c|}
\hline \multirow{2}{*}{$\begin{array}{c}\text { Estimate of } \\
\text { standard diviation }\end{array}$} & \multicolumn{3}{|c|}{ average returns } \\
\cline { 2 - 4 } & market model & $\begin{array}{c}\text { constant exp. } \\
\text { returns }\end{array}$ & $\begin{array}{c}\text { market adjusted } \\
\text { returns }\end{array}$ \\
\cline { 2 - 4 } & -0.0051 & a) on event day 1 \\
\hline standard & 0.0016 & 0.0025 & -0.0034 \\
\hline sample & 0.0091 & 0.0173 & 0.0023 \\
\hline \multirow{2}{*}{\begin{tabular}{c} 
s. b) cumulated over days $1, \ldots, 30$ \\
\hline standard
\end{tabular}} & -0.0037 & -0.0145 & -0.0047 \\
\hline sample & 0.0088 & 0.0137 & 0.0125 \\
\hline
\end{tabular}

In the case of the market model, these expressions must be augmented by a term which accounts for the error in estimating the coefficients of the model. These terms are however rather small for an estimating window of length 200 an can be neglected. Also, there is some overlap in the post event windows of the 2004 hurricanes which induces positive correlation among the respective cumulated abnormal returns, which in turn leads to an underestimation of the variance (see e.g. Krämer and Kiviet 1992). As this overlap affects only 4 of the 20 events, this effect is likewise here neglected. A much more serious drawback is a possible increase in the return variance induced by the event (Boehmer et al. 1991). We have checked this for our sample and have 
indeed found a larger empirical variance subsequent to the event in almost all cases. Therefore, table 3 also shows alternative estimates of the abnormal returns standard deviations by simply taking the empirical standard deviations of the observed returns. These estimates are less precise if there is no event induced increase in the variance, but more reliable if the variance does indeed increase.

Keeping these caveats in mind, table 3 confirms what we have already seen in figures $1-4$ : There is a statistically significant negative abnormal return on event day 1 (at least if we confine ourselves to the market and constant expected return models and to the standard variance estimates), while the null hypothesis that there is no cumulated abnormal return at the end of the event window cannot be rejected regardless of the model and the variance estimate which we use.

\section{Conclusion}

Our empirical findings are unequivocal in that large scale desasters do not negatively affect the insurance industry as a whole. Adverse shocks to equity are compensated by either outward shifts of the demand curve or a demand independent ability to raise premiums or both. This confirms recent results on total markets by Chen and Siems (2004), but is in stark contrast to the finding by Brown et al (2004) that government interventions which are designed to mitigate the effects of disasters do not help the industry at all. 


\section{References}

Aiuppa, Thomas; Robert, A.; Carney J. and Krueger, Thomas M. (1993): "An examination of insurance stock prices following the 1989 Loma Prieta Earthquake." Journal of Insurance Issues and Practices 16, 1 - 14.

Arnold, N. Scott (2002), "The role of government in responding to natural catastrophes", Chapter One in Liberty and Hard Cases, edited by Tibor R. Machan, Hoover Institution Press Publication No. 492.

Brown, Jeffrey R., Cummins, David S., Lewis, Christopher M. and Wei, Ran (2004): "An empirical analysis of the economics impact of federal terrorism insurance," NBER working paper No. 10388.

Boehmer, Ekkehart; Musumeci, Jim and Poulsen, Annette (1991): "Event-study methodology under conditions of event-induced variance." Journal of Financial Economics 30, 253 - 272.

Brown, Stephen and Warner, Jerold B. (1985): "Using daily stock returns: the case of event studies." Journal of Financial Economics 14, 3 - 33.

Chen, Andrew H. und Siems, Thomas F. (2004): „The effects of terrorism on global capital markets,“" European Journalof Political economy 20, 349-366.

Cummins, J. David and Danzon, Patricia M. (1997): "Price, financial quality and capital flows in insurance markets." Journal of Financial Intermediation 6, 3 38 .

Cummins, J. David; Lewis, Christopher M. and Phillips, Richard D. (1999): "Pricing excess of loss reinsurance contracts against catastrophic loss." In K.A. Froot, ed.. The Financing of Catastrophe Risk (Chicago: University of Chicago Press).

Cummins, J. David and Lewis, Ch. U. (2002): "Catastrophic events, parameter uncertainly and the breakdown of implicit long-term contracting in the insurance market: the case of terrorism insurance." Wharton discussion paper 02-40.

Froot, Kenneth A. and O'Connell, Paul G.J. (1999): "The pricing of US catastrophe reinsurance." In K.A. Froot, ed.. The Financing of Catastrophe Risk (Chicago: University of Chicago Press).

Gron, Anne (1994): "Capacity constraints and cycles in property-casualty insurance markets." Rand Journal of Economics 25, 110 - 127.

Krämer, W. and Kiviet, J. (1992): "The bias of $\mathrm{s}^{2}$ in the linear regression model with autocorrelated errors," The Review of Economics and Statistics 74, 362-365.v

Lamb, Reinhold (1995): "An exposure-based analysis of property-liability insurer stock values around Hurricane Andrew." Journal of Risk and Insurance 62, $111-123$.

MacKinlay, A. Craig (1997): "Event studies in economics and finance." Journal of Economic Literature 35, 12 - 39. 
Ploberger, W. and Krämer, W. (1990): "The local power of the CUSUM and CUSUM of squares tests," Econometric Theory 6, 335-347.

Ploberger, W. and W. Krämer (1992): „The CUSUM-test with OLS-residuals,“ Econometrica 60, 271-285.

Shelor, Roger M.; Anderson, Dwight C. and Cross, Mark (1992): "Gaining form loss: Property-liability insurer stock values in the aftermath of the 1989 California earthquake." Journal of Risk and Insurance 5, 476 - 488.

Swiss Re (2004a): "Natural catastrophes and man-made disasters in 2003: many fatalities, comparatively moderate insured losses" Sigma No. 1.

Swiss Re (2004b): "Preliminary Swiss Re sigma estimates of catastrophe losses in 2004, 16 December. 